\title{
Fat Metaplasia in Inflammatory Sacroiliitis and in Nonrheumatic Conditions: A Step Toward Better Characterization
}
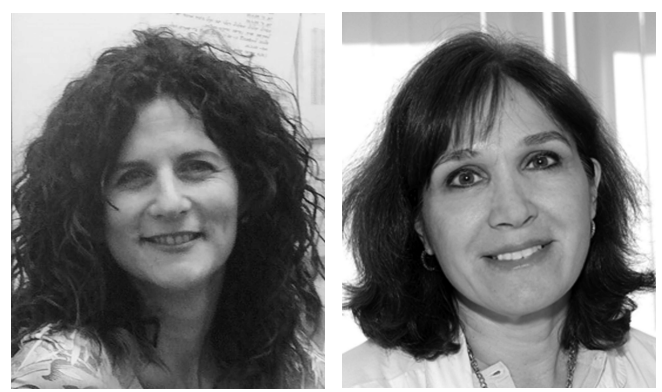

Spondyloarthritis (SpA), a group of inflammatory diseases of which ankylosing spondylitis is the prototype, typically presents with inflammation of the sacroiliac joints (SIJ), or sacroiliitis ${ }^{1,2}$. The article by Ziegeler, et al in this issue of The Journal ${ }^{3}$ describes the prevalence of periarticular sacroiliitis-like structural magnetic resonance imaging (MRI) changes of a patient population with low back pain and clinically suspected sacroiliitis. The authors' main results provide important new insights into the MRI distribution pattern of periarticular fat metaplasia of the SIJ across different age groups in nonrheumatic subjects and numerous specific pathologic conditions.

To date, MRI is considered the most sensitive and specific imaging modality for diagnosing and evaluating SIJ inflammation in patients with early disease ${ }^{4}$. The introduction of biological drugs such as the tumor necrosis factor- $\alpha$ receptor blocker group and their beneficial effect on SpA resulted in an accelerated use of MRI for early detection of sacroiliitis ${ }^{4,5}$. As a result, an increasing number of SIJ MRI are performed each year on patients with suspected sacroiliitis ${ }^{6}$. The main acute inflammatory finding detected on MRI, but not on radiographs, is periarticular bone marrow edema, or osteitis. Structural changes such as erosions, sclerosis, and ankylosis can be seen on pelvic radiographs and computed tomography in advanced, already established disease. However, like osteitis, periarticular fatty replacement, or fat metaplasia, is not seen on radiographs and can be reliably detected only on MRI.

The Assessment of SpondyloArthritis international Society (ASAS) classification system for axial SpA (axSpA) is based on whether patients meet clinical or imaging criteria $^{5,7}$. The MRI arm of the ASAS criteria is based on the presence of osteitis of the SIJ for classifying patients with nonradiographic axSpA ${ }^{8}$, although the importance of structural lesions for additive diagnostic information was recognized in an ASAS update ${ }^{7}$.

None of the MRI findings seen in sacroiliitis, whether active or structural, are pathognomonic of axSpA, and all were described in other clinical settings and entities. For example, diffuse periarticular osteitis of the SIJ, the hallmark of axSpA, was described in the MRI of peripartum women ${ }^{9}$, while minor amounts of osteitis were even described in healthy individuals ${ }^{10}$. Moreover, noninflammatory diseases such as spinal degenerative changes, tumors, or infections may present as inflammatory-type back pain (IBP) that clinically mimics sacroiliitis ${ }^{11}$. Thus, relying only on MRI findings as currently defined, even in the presence of IBP, may lead to an erroneous diagnosis of sacroiliitis. Therefore, scrutinized investigation of each of the active and structural sacroiliitis-related MRI findings in different cohorts with different disease entities should serve to better characterize and fine-tune each finding, potentially improving the sensitivity and specificity of the MRI diagnosis of inflammatory sacroiliitis.

In their study, Ziegeler, et al, to evaluate fat metaplasia appearance in subjects with no rheumatic diseases, define fat metaplasia beyond the known fat signal characterization used thus far. They outline a semiquantitative grading system of periarticular fat distribution based on its appearance and extent. This straightforward and easy-to-use grading system is accompanied by a clear and demonstrative figure. The grades range from 0 for normal bone marrow signal, to 5 patterns of fat metaplasia: focal (1), patchy (2), band-like (3), extensive but subtotal (4), and extensive (5). Overall, fat metaplasia was commonly detected in all subjects, increased in prevalence with age, and had an age-dependent pattern transition from patchy to more confluent.

Fat metaplasia is presumably an intermediate stage between active inflammation and new bone formation ${ }^{12}$. In sacroiliitis, this may explain the presence of sacroiliac fat-related signal not only in the periarticular area replacing subsiding inflammation, but also within the joint cavity replacing erosive changes (backfill) ${ }^{13}$. However, because its histopathology is not yet clear, fat metaplasia may be a misnomer; fat signal intensity on MRI does not necessarily imply a process of transformation of the inflamed marrow tissue into adipose innate tissue.

Indeed, lipid-laden macrophages are found in several

See Fat metaplasia in SIJ without rheumatological disease, page 915 
types of chronic inflammatory lesions and play a role in the resolution of inflammation not only by endocytic clearance, but also through reduced secretion of proinflammatory cytokines ${ }^{14}$. Further, homeostasis after subsiding inflammation is an actively regulated process facilitated by several novel lipid mediators such as lipoxins and resolvins ${ }^{15,16}$. All, if indeed present in the periarticular SIJ region in the process of inflammation healing, may contribute to the fatty signal seen on MRI.

The conversion of red bone marrow to yellow fatty marrow has a predictable pattern of progression in the skeleton as a whole as well as in individual bones, starting at the peripheral appendicular skeleton and gradually advancing toward the axial skeleton ${ }^{17}$. Accordingly, MRI detects increased amounts of fatty marrow with age in the pelvis, although periarticular hematopoietic marrow remains predominant in the sacroiliac region ${ }^{18}$. This may be explained by anatomical studies that have shown that red marrow distribution patterns in individual bones follow the distribution of their vascular systems and that the subchondral area of the SIJ, among others, has a rich vascular network ${ }^{19}$.

Periarticular degenerative changes in the SIJ are seen as small foci of high signal intensity representing the known osteoarthrotic bone marrow lesions $(\mathrm{BML})^{20}$. Thus, the periarticular focal pattern of fat metaplasia described by Ziegeler, et al is probably the result of the healing process of such BML. The other commonly seen patterns of patchy and extensive fat metaplasia are in line with the progression pattern of fat conversion seen with age.

Looking further into the pattern of fat distribution in Ziegeler, et al's current cohort reveals that grade 3, or the band-like fat metaplasia pattern, was uncommon in the entire cohort. This pattern bears the most resemblance to the semilunar periarticular osteitis typical of inflammatory sacroiliitis. Currently, structural changes, including fat metaplasia, are not considered diagnostic of sacroiliitis and axSpA in the absence of osteitis 5,7 . However, the pattern of periarticular fat distribution in inflammatory sacroiliitis in the majority of patients follows the pattern of osteitis (Figure 1), suggesting a healing process is taking place in the affected inflamed periarticular $\operatorname{areas}^{21}$. Therefore, an important conclusion from the Ziegeler, et al study is that a band-like pattern, unlike the other patterns seen increasingly with age, is not a normal variant of an aging joint but rather (just like the osteitis pattern mentioned above) implies a resolved inflammatory sacroiliitis

Interestingly, a comparable semilunar band-like pattern of osteitis that is replaced by fat metaplasia is well recognized

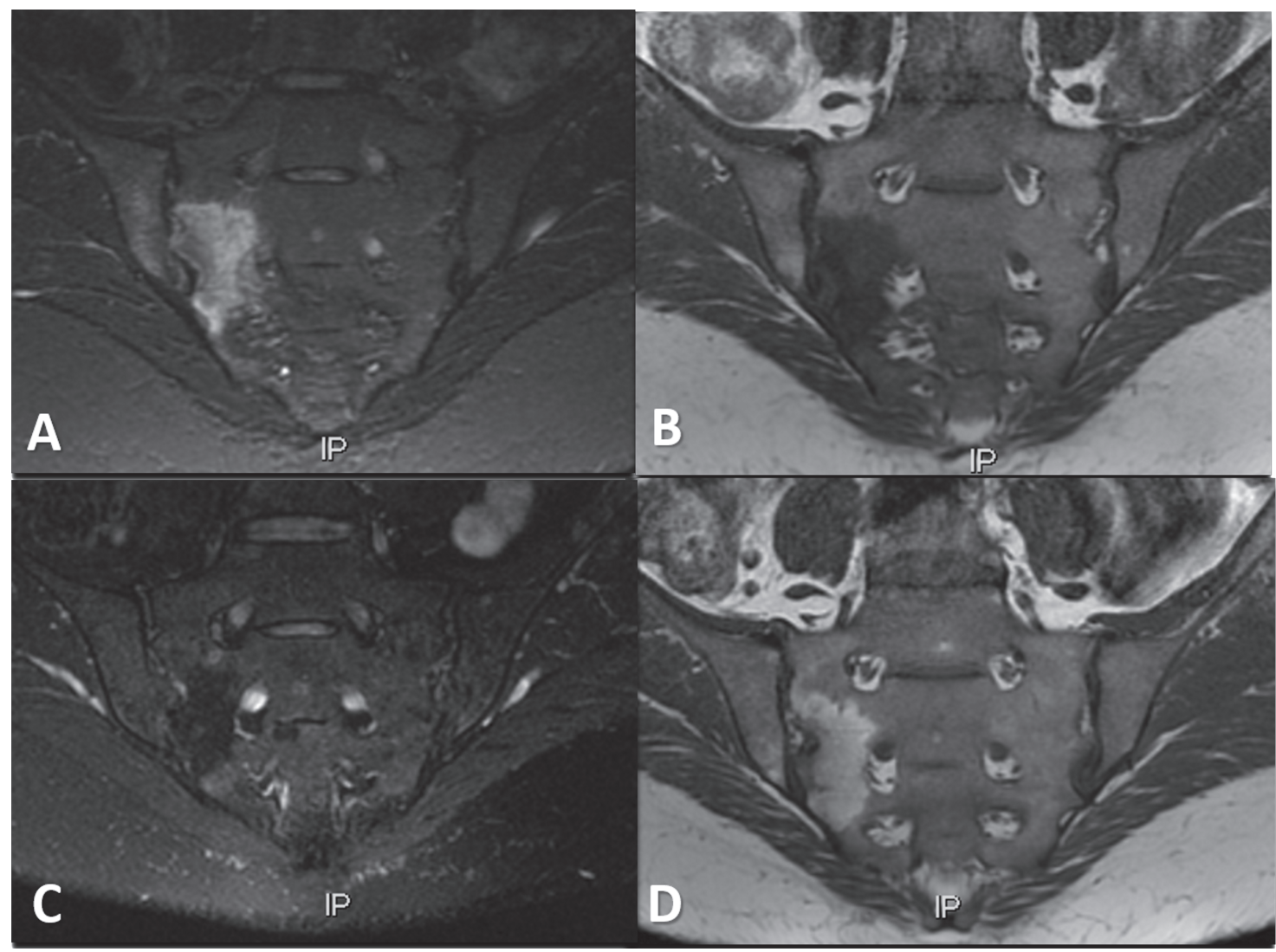

Figure 1. Semicoronal STIR (A, C) and T1 (B, D) images of the sacroiliac joints of a 35-year-old woman with spondyloarthritis at diagnosis (A, B) and 4 years later (C, D). A semilunar, band-like right sacral sided osteitis clearly seen at diagnosis (A) resolves on the followup examination $(\mathrm{C})$ and is replaced with fat metaplasia following the osteitis pattern (D). STIR: short-tau inversion recovery.

Personal non-commercial use only. The Journal of Rheumatology Copyright (C) 2018. All rights reserved. 
in the degenerative spine, where it is called the Modic type endplate changes ${ }^{22}$. The endplate osteitis pattern (Modic I) is thought to represent inflammation resulting from a disc or endplate damage while the fat metaplasia pattern (Modic 2) is assumed to result from a healing process with increased bone turnover and fibrosis ${ }^{23,24}$. Despite the MRI pattern similarity, the natural history of the 2 entities is quite different; while inflammation and fat metaplasia in the SIJ tend to lead to ankylosis, no such ankylosis is seen in the degenerative spine where resolution of the findings with endplate sclerosis (Modic 3) typically ensues. The different natural history suggests different pathogenesis and potentially different histologic composition of the periarticular fat metaplasia.

Fat metaplasia is a common finding in the pelvis with different patterns of periarticular, sacroiliac distribution. The band-like fat metaplasia pattern is less commonly seen in the nonrheumatic population. Further analysis of the acute and structural sacroiliitis-related MRI findings in different cohorts may aid in refining the MRI diagnostic performance.

\section{IRIS ESHED, MD, \\ Associate Professor, MERAV LIDAR, MD, \\ Associate Professor, Rheumatology Unit, Sheba Medical Center, Tel Hashomer, Affiliated to the Sackler Faculty of Medicine, Tel Aviv University, Tel Aviv, Israel.} Department of Diagnostic Imaging;

Address correspondence to Prof. I. Eshed, Department of Diagnostic Imaging, Sheba Medical Center, Tel Hashomer 52621, Israel. E-mail: iriseshed@gmail.com

\section{REFERENCES}

1. Brandt J, Bollow M, Häberle J, Rudwaleit M, Eggens U, Distler A, et al. Studying patients with inflammatory back pain and arthritis of the lower limbs clinically and by magnetic resonance imaging: many, but not all patients with sacroiliitis have spondyloarthropathy. Rheumatology 1999;38:831-6.

2. Dougados M, Baeten D. Spondyloarthritis. Lancet 2011;377:2127-37.

3. Ziegeler K, Eshkal H, Schorr C, Sieper J, Diekhoff T, Makowski MR, et al. Age- and sex-dependent frequency of fat metaplasia and other structural changes of the sacroiliac joints in patients without axial spondyloarthritis: a retrospective, cross-sectional MRI study. J Rheumatol 2018;45:915-21.

4. Hermann KG, Bollow M. Magnetic resonance imaging of sacroiliitis in patients with spondyloarthritis: correlation with anatomy and histology. Rofo 2014;186:230-7.

5. Rudwaleit M, Jurik AG, Hermann KG, Landewé R, van der Heijde $\mathrm{D}$, Baraliakos X, et al. Defining active sacroiliitis on magnetic resonance imaging (MRI) for classification of axial spondyloarthritis: a consensual approach by the ASAS/OMERACT MRI group. Ann Rheum Dis 2009;68:1520-7.

6. Abitbul V, Lidar M, Shabshin N, Flusser G, Eshed I. [Magnetic resonance imaging for the diagnosis of sacroiliitis in Israel: our experience in the last five years]. [Article in Hebrew] Harefuah 2011;150:563-7, 619, 618 .
7. Lambert RG, Bakker PA, van der Heijde D, Weber U, Rudwaleit M, Hermann KG, et al. Defining active sacroiliitis on MRI for classification of axial spondyloarthritis: update by the ASAS MRI working group. Ann Rheum Dis 2016;75:1958-63.

8. Rudwaleit M, Landewé R, van der Heijde D, Listing J, Brandt J, Braun J, et al. The development of Assessment of SpondyloArthritis international Society classification criteria for axial spondyloarthritis (part I): classification of paper patients by expert opinion including uncertainty appraisal. Ann Rheum Dis 2009;68:770-6.

9. Eshed I, Miloh-Raz H, Dulitzki M, Lidar Z, Aharoni D, Liberman $B$, et al. Peripartum changes of the sacroiliac joints on MRI: increasing mechanical load correlating with signs of edema and inflammation kindling spondyloarthropathy in the genetically prone. Clin Rheumatol 2015;34:1419-26.

10. Weber U, Lambert RG, Ostergaard M, Hodler J, Pedersen SJ, Maksymowych WP. The diagnostic utility of magnetic resonance imaging in spondylarthritis: an international multicenter evaluation of one hundred eighty-seven subjects. Arthritis Rheum 2010;62:3048-58.

11. Jans L, Van Praet L, Elewaut D, Van den Bosch F, Carron P, Jaremko JL, et al. MRI of the SI joints commonly shows non-inflammatory disease in patients clinically suspected of sacroiliitis. Eur J Radiol 2014;83:179-84.

12. Maksymowych WP, Wichuk S, Chiowchanwisawakit P, Lambert RG, Pedersen SJ. Fat metaplasia and backfill are key intermediaries in the development of sacroiliac joint ankylosis in patients with ankylosing spondylitis. Arthritis Rheumatol 2014;66:2958-67.

13. Weber U, Pedersen SJ, Ostergaard M, Rufibach K, Lambert RG, Maksymowych WP. Can erosions on MRI of the sacroiliac joints be reliably detected in patients with ankylosing spondylitis? - A cross-sectional study. Arthritis Res Ther 2012;14:R124.

14. Sica A, Mantovani A. Macrophage plasticity and polarization: in vivo veritas. J Clin Invest 2012;122:787-95.

15. Serhan CN. Lipoxins and aspirin-triggered 15-epi-lipoxins are the first lipid mediators of endogenous anti-inflammation and resolution. Prostaglandins Leukot Essent Fatty Acids 2005;73:141-62.

16. Serhan CN, Clish CB, Brannon J, Colgan SP, Chiang N, Gronert K. Novel functional sets of lipid-derived mediators with antiinflammatory actions generated from omega-3 fatty acids via cyclooxygenase 2-nonsteroidal antiinflammatory drugs and transcellular processing. J Exp Med 2000;192:1197-204.

17. Ricci C, Cova M, Kang YS, Yang A, Rahmouni A, Scott WW Jr, et al. Normal age-related patterns of cellular and fatty bone marrow distribution in the axial skeleton: MR imaging study. Radiology 1990;177:83-8.

18. Levine CD, Schweitzer ME, Ehrlich SM. Pelvic marrow in adults. Skeletal Radiol 1994;23:343-7.

19. Vande Berg BC, Malghem J, Lecouvet FE, Maldague B. Magnetic resonance imaging of the normal bone marrow. Skeletal Radiol 1998;27:471-83.

20. Alliston T, Hernandez CJ, Findlay DM, Felson DT, Kennedy OD. Bone marrow lesions in osteoarthritis: what lies beneath. J Orthop Res 2017 Dec 21 (E-pub ahead of print).

21. Maksymowych WP. Imaging in axial spondyloarthritis: evaluation of inflammatory and structural changes. Rheum Dis Clin North Am 2016;42:645-62.

22. Modic MT, Ross JS. Lumbar degenerative disk disease. Radiology 2007;245:43-61.

23. Dudli S, Fields AJ, Samartzis D, Karppinen J, Lotz JC. Pathobiology of Modic changes. Eur Spine J 2016;25:3723-34.

24. Quattrocchi CC, Alexandre AM, Della Pepa GM, Altavilla R, Zobel BB. Modic changes: anatomy, pathophysiology and clinical correlation. Acta Neurochir Suppl 2011;108:49-53. 